\title{
Demographic Patterns and Household Saving in China
}

\author{
Chadwick R. Curtis, Steven Lugauer and Nelson C. Mark*
}

February 14, 2011

\begin{abstract}
This paper studies the effect that changing demographic patterns have had on the household saving rate in China. We undertake a quantitative investigation using an overlapping generations (OLG) model where agents live for 85 years. Consumers begin to exercise decision making when they are 18. From age 18 to 60 , they work and raise children. Dependent children's utility enter into parent's utility where parents choose the consumption level of the young until they leave the household. Working agents give a portion of their labor income to their retired parents and save for their own retirement while the aged live on their accumulated assets and support from their children. Remaining assets are bequeathed to the living upon death We parameterize the model and take future demographic changes, labor income and interest rates as exogenously given from the data. We then run the model from 1963 to 2009 and find that the model accounts for nearly all the observed increase in the household saving rate.
\end{abstract}

Keywords: Saving, Life-Cycle, China, Demographics, Overlapping Generations

JEL: E2, J1

\footnotetext{
*Author's affiliations are University of Notre Dame (ccurtis.1@nd.edu), University of Notre Dame (Steven.Lugauer.1@nd.edu), University of Notre Dame and NBER (nmark@nd.edu) respectively. For useful comments, we thank Joe Kaboski and seminar participants at the Federal Reserve Bank of St. Louis, Notre Dame's macro research group, Notre Dame's Kellogg Institute, and the Hong Kong Monetary Institute.
} 


\section{Introduction}

In 2008, the household saving rate in China was a whopping 27 percent. Chinese households have not always been such high savers, however. The 27 percent figure, certainly high by international standards, is also high in comparison to their own saving in an earlier period. From 1959 to 1977, the household saving rate averaged only 3.9 percent-quite a bit lower than the average rate of 8.9 percent observed in the US over the same period. The transition from low to high saving in China began around 1978, the time that market-based economic reforms were put in place. But in addition to a changing economic landscape, some large demographic changes were taking place. Fertility rates of 6 children per woman in the 1950s declined to less than 2 and the number children aged 1 to 17 per parent aged person (ages 18 to 60 ) fell from 0.73 to 0.36 . Also, people are living longer and the increase in life-expectancy has helped raise the number of aged (ages 61 to 85) per worker (ages 18 to 60 ) from 0.14 to 0.17 and is projected to increase to 0.39 by 2030 .

This paper seeks to understand the time-path of household saving in China from 1963 to 2008 and the role played by the changing demographics. We undertake a quantitative investigation using an overlapping generations (OLG) model where agents live for 85 years. Consumers begin to exercise decision making when they are 18. From age 18 to 60 , they work and raise children. Dependent children's utility enter into parent's utility where parents choose the consumption level of the young until they leave the household. Working agents give a portion of their labor income to their retired parents and save for their own retirement. The aged live on their accumulated assets and support from their children. Remaining assets are bequeathed to the living upon death.

Our set-up allows demographic variations to affect the saving rate through more than one channel. First, the household saving rate is inversely related to the fertility rate. Having fewer "mouths to feed," raises the availability of resources that can be saved for the future. Second, due to the importance of children as a source of retirement income, when the current working generation has fewer children their base for old-age support has shrunk so those working will want to increase saving for their retirement. Finally, most saving tends to occur between the ages of 40 and 65. Aggregate saving increases when there are more consumers are in this age group, as is currently the case.

Our analysis allows variation in at wages and interest rates, to affect the saving rate. We parameterize the model and take future demographic changes, labor income and interest rates as exogenously given from the data. We then run the model from 1963 to 2009 and find that the model can account for nearly all the observed increase in the household saving rate. ${ }^{1}$

The high household saving rate in China has attracted the attention of many researchers. Some authors have investigated clever and nonstandard channels. Wei and Zhang (2009) hypothesize that the male sex imbalance, resulting from a Chinese cultural preference for sons and the onechild policy of population control, is the driving force in raising the saving rate. Their story is that families whose only child is a son compete for spouses in the marriage market through wealth accumulation and that the intensity of this wealth competition has increased in recent

\footnotetext{
${ }^{1}$ Data exists beginning in 1953 but we begin our simulations in 1963 to avoid extreme outcomes associated with the Great Leap Forward and the Great Famine (1961).
} 
years. While the "excess male" hypothesis predicts lower saving by parents of daughters, Banerjee et al (2010) report evidence that saving by these households is higher than by parents of sons. Their explanation is that due to the cultural convention that sons (not daughters) will provide for parents in old age, parents of daughters need to save more so as to provide for themselves in their retirement. $^{2}$

Our paper does not distinguish agents by gender and is more closely related to the empirical studies of Modigliani and Cao (2004) and Horioka and Wan (2007), who investigate life-cycle determinants of saving. These authors show that China's age structure and saving rate have been related over a 50 year period but they do so using a form of the dependency ratio in reduced form regressions and do not control for the entire population distribution. In our paper the entire age distribution, both current and future, have an impact on the saving decision.

Other work that employs the OLG framework to study saving include Ferrero (2010), who finds an important role for demographics in explaining the long run trend in US saving relative to other G6 countries, Krueger and Ludwig (2007), who show the importance of demographic change in a multi-country OLG model, Chen et al (2006), who argue that the decline in population growth has had only a small effect on the Japanese saving rate and Song and Yang (2010) who study the effects of a flattening of the age-earnings profile on Chinese household saving. Two dimensions along which our paper differs from these, however, is that we allow consumption by children to enter directly into household utility as in Barro and Becker (1989) model and that we allow an explicit bequest motive. Our paper also makes contact with the broader literature on how demographic changes affect the macro-economy. Shimer (2001) details how the age distribution impacts unemployment rates; Feyrer (2007) relates demographic change to productivity growth; and Jaimovich and Siu (2009) and Lugauer (2009) connect the age distribution to the magnitude of business cycles.

The economic importance of China in the world economy is difficult to overstate. Simply by virtue of China's 1.3 billion people it's economy is large in an absolute terms and has overtaken Japan as the world's second largest in terms of aggregate GDP. The saving rate in China exceeds that of nearly every other country, and Chinese savings have been used to purchase large amounts of assets denominated in US dollars. The US current account deficit with China was nearly $\$ 270$ billion in 2008, about $2 \%$ of US GDP. The high household saving rate in China helps make these gigantic capital flows possible.

The remainder of the paper is organized as follows. The next section presents the data that underlies our analysis. Section 3 presents the model used in the quantitative analysis. Parameterization of the model is discussed in Section 4, the main results are presented in Section 5 and Section 6 concludes.

\footnotetext{
${ }^{2}$ See also Chaman and Prasad (2010) who argue that saving has responded to provide for a rising private burden of expenditures on housing, education and health care.
} 


\section{The data}

The historical and projected demographic estimates come from the United Nations World Population Prospects. The Chinese household saving rate data comes from Modigliani and Cao (2004) and various issues of the China Statistical Yearbook. We report and use the available information as provided by these sources and without modification. ${ }^{3}$

Figure 1 plots the household saving rate (household saving divided by household income) in China from 1963 to 2009 that we seek to understand. As can be seen, before 1978 the saving rate hovered at levels similar to those observed in developed countries. The post 1978 high saving rate regime, though, is punctuated by sizeable fluctuations. In a short 6 year span between 1978 and 1984, the saving rate increased by 15 percent. From 1985 to 1988, it falls to 10 percent, then resumes more or less a steady upward trend to the present time.

To place the saving rate in the international context, Table 1 shows household saving as a percent of GDP for five countries in 2004. Recent Chinese household saving has been high even in comparison to its Asian neighbors Japan and Korea.

Table 1: Household Saving as a Percent of GDP in 2004

\begin{tabular}{cccccc}
\hline \hline & China & USA & France & Japan & Korea \\
\hline Saving Rate & 18.5 & 5.1 & 10.9 & 6.2 & 8.0 \\
\hline
\end{tabular}

Figure 2 shows that the age distribution in China has changed in large ways. In this figure, the ratio of the population aged 0 to 17 to the number aged 18 to 60 (labeled young to working) provides us with a measure of family size. Family size is relatively flat until 1975 then falls steadily through 2009. The other series shown in the figure is the old-age dependency ratio (aged 60 to 85 relative to working aged). The old-age dependency ratio begins to rise around 1990 and is projected to trend upwards sharply after 2009. The current working age population has relatively few retirees to support, but when the current workers retire, there will be relatively few workers. The dramatic change comes from the decline in fertility and also an increase in the average life span.

\footnotetext{
${ }^{3}$ See Curtis and Mark (2010) for more about Chinese data and studying China using standard economic models.
} 
Table 2: Total Fertility Rates

\begin{tabular}{lccc}
\hline \hline Year & China & USA & Japan \\
\hline $1950-54$ & 6.1 & 3.4 & 3.0 \\
$1955-59$ & 5.5 & 3.7 & 2.2 \\
$1960-64$ & 5.6 & 3.3 & 2.0 \\
$1965-69$ & 5.9 & 2.5 & 2.0 \\
$1970-74$ & 4.8 & 1.8 & 2.1 \\
$1975-79$ & 2.9 & 1.8 & 1.8 \\
$1980-84$ & 2.6 & 1.8 & 1.8 \\
$1985-89$ & 2.0 & 1.9 & 1.7 \\
$1990-94$ & 1.8 & 2.0 & 1.5 \\
$1995-99$ & 1.8 & 2.0 & 1.4 \\
$2000-04$ & 1.8 & 2.0 & 1.3 \\
$2005-09$ & 1.8 & 2.1 & 1.3 \\
\hline
\end{tabular}

To place China's fertility rate in the international context, Table 2 shows fertility rates for China, the US and Japan. Chinese women who were having, on average, over six children between 1950 and 1954, now slightly more than 1 . The variations in China's fertility rate are due in large part to the government's policy on family planning. As is well known, China's one-child policy was implemented in 1978 and officially remains in effect although enforcement in the rural areas is not so strict. At present, the policy is enforced at the provincial level and enforcement varies. Perhaps lesser known is that various (although less effective) fertility reduction programs had been implemented at least since 1964. As can be seen, fertility rates had already begun to decline in response to the 1971 "Later-Longer-Fewer" campaign where the suggestion was for two children in urban areas and three in rural areas (Kaufman et al (1989)). ${ }^{4}$

Figure 3 illustrates how closely the household saving rate and the working age proportion of the population move together. This makes sense since only people who are earning income can save, and the majority of income for the majority of people will be labor income. But in addition to this composition effect, the working aged population corresponds in age, roughly to households with dependent children. Over the sample, the proportion of working cohorts is rising at the same time that family size is falling which provides a second channel for the saving rate to rise.

Figure 4 plots the saving rate with the log real wage which we calculate as the annualized marginal product of labor. The wage shows substantial volatility in the 1960s, reflecting the hard times associated with the Great Famine. The wage has an apparent trend break in 1978 where wages grow faster in the post reform period. The relatively low wage growth before 1978 should tend to induce a higher saving rate and the relatively high wage growth after 1978 should induce a lower saving rate. Ex ante, the dynamics of labor income seem to work against the way a successful model would work to account for the data.

\footnotetext{
${ }^{4}$ In our quantitative analysis, the age distribution is assumed to be exogenously determined. The strong response of fertility to policy provides some justification for this assumption.
} 
To summarize, the correlation between the large increase in the saving rate and the dramatic demographic transition represents the main stylized fact we wish to explore. Standard life cycle considerations predict that household saving should increase in response to exogenously mandated reductions in family size because (a) fewer mouths to feed frees up resources that can be saved and (b) looking ahead at fewer children to help provide for old age means people need to save more for retirement. Additionally, we should observe that the household saving rate is increasing in the proportion of the working age population simply through changes in the composition (or share) of life-cycle savers. In addition, high labor income growth should work to depress the saving rate whereas low income growth should encourage greater saving. The pattern of income growth and demographics (low income growth, large families, relatively few working age before 1978 and the reversal after 1978) seen in the data influence the saving decision in different directions. To sort out these effects and to examine which ones dominate, we turn to the OLG model.

\section{An Overlapping Generations Model of Saving}

We work with a partial equilibrium model that consists of decision making households of cohort age ranging from 18 to 85 . A representative firm employs all working age agents and pays them the market wage which is given by the marginal product of labor. A national financial intermediary clears excess supply or demand for capital on the international market. The age distribution, wage, and interest rate are given exogenously, and all agents know the current and future values.

\subsection{Consumers}

Consumers live 85 periods or years. At any point in time, 85 generations are present but only those aged 18 to 85 make decisions. The population is classified into 5 not necessarily disjoint groups: Children (age 0 to 17), parents (age 18 to 60 ) who are also workers and adult children, and retirees (age 61 to 85). Let $N_{t}^{c}, N_{t}^{p}, N_{t}^{w}, N_{t}^{a c}$, and $N_{t}^{r}$ be the number of people in these respective groups at time $t$ and let $N_{t}$ be the total population. For the first 17 years, people live as children and are dependent upon their parents. They do not save and consume what their parents choose for them. Parental and children's consumption enter separately into parental utility, as in Barro and Becker (1989). People work and earn labor income from ages 18 to 60. During retirement, people live off their accumulated assets and transfers received from their working aged children. People die with certainty at age 85 . In the last year of life, utility depends on consumption in that year and a bequest that is distributed in the year after death to adult aged (35 to 65) children.

\subsubsection{Budget constraints}

Let $c_{t}^{i}$ be the consumption of the decision making cohorts $i \in[18,85]$. Individuals in cohorts $i \in[18,60]$ have $n_{t}=N_{t}^{c} / N_{t}^{p}$ dependent children living with them, each of whom consume in the amount $c_{t}^{c, i}$. During the parenting years, agents choose their own consumption $c_{t}^{i}$, their dependent children's consumption $c_{t}^{c, i}$, and assets $a_{t+1}^{i+1}$ to take into the next period. They also transfer a 
fraction $\tau_{t}$ of their labor income $w_{t}$ to support their elderly parents. The inheritance is $B_{t}^{i}=n_{t}^{b} a_{t+1}^{85}$ for cohorts $i \in[35,65]$ and zero otherwise, where $n_{t}^{b}=\left(N_{t}^{85} / N_{t}^{a c}\right)$ and $N_{t}^{85}$ is the number of people aged 85 in period $t$. The budget constraints during these years are

$$
n_{t} c_{t}^{c, i}+c_{t}^{i}+a_{t+1}^{i+1}=\left(1-\tau_{t}\right) w_{t}+\left(1+r_{t}\right) a_{t}^{i}+B_{t}^{i}, \quad i \in[18,60] .
$$

and the budget constraint facing retired cohorts is

$$
c_{t}^{i}+a_{t+1}^{i+1}=P_{t}+\left(1+r_{t}\right) a_{t}^{i}+B_{t}^{i}, \quad i \in[61,85],
$$

where $P_{t}=\frac{N_{t}^{w}}{N_{t}^{r}} \tau_{t} w_{t}$ is the per retiree transfer received from adult children. Asset holdings are required to be non negative (consumers are not allowed to borrow).

\subsubsection{Preferences}

During those years in which parents make decisions for children, we follow Barro and Becker (1989) and use the period utility function

$$
u_{t}^{i}\left(c_{t}^{c, i}, c_{t}^{i}\right)=\mu\left(n_{t}\right)^{\eta}\left(\frac{\left(c_{t}^{c, i}\right)^{1-\sigma}}{1-\sigma}\right)+\left(\frac{\left(c_{t}^{i}\right)^{1-\sigma}}{1-\sigma}\right), \quad i \in[18,47]
$$

where $\mu<1$ and $\eta<1$ determine the degree to which parents care for their children and $\frac{1}{\sigma}>0$ is the elasticity of intertemporal substitution. These are interpreted as single-parent households each with $n=N^{c} / N^{p}$ dependent children.

In the last year of life, utility is defined over consumption for that year $c_{t}^{85}$ and assets $a_{t+1}^{85}$ bequeathed to the surviving $n_{t}^{b}$ children' of the oldest cohort. The period utility function for agents in the last year of life is

$$
u_{t}^{85}\left(c_{t}^{85}, a_{t+1}^{85}\right)=\mu\left(n_{t}^{b}\right)^{\eta}\left(\frac{\left(a_{t+1}^{85}\right)^{1-\sigma}}{1-\sigma}\right)+\left(\frac{\left(c_{t}^{85}\right)^{1-\sigma}}{1-\sigma}\right) .
$$

Utility for the remaining cohorts is the standard isoelastic function

$$
u_{t}^{i}\left(c_{t}^{i}\right)=\frac{\left(c_{t}^{i}\right)^{1-\sigma}}{1-\sigma}, \quad i \in[61,84] .
$$

Thus, in the first year of decision making, lifetime utility for the representative 18 year-old cohort 
in year $t$ is

$$
\begin{aligned}
U_{t}^{18} & =\sum_{j=0}^{42} \beta^{j}\left(\mu\left(n_{t}\right)^{\eta}\left(\frac{\left(c_{t+j}^{c, j+18}\right)^{1-\sigma}}{1-\sigma}\right)+\left(\frac{\left(c_{t+j}^{j+18}\right)^{1-\sigma}}{1-\sigma}\right)\right) \\
& +\sum_{j=43}^{66} \beta^{j}\left(\frac{\left(c_{t+j}^{j+18}\right)^{1-\sigma}}{1-\sigma}\right) \\
& +\left(\mu\left(n_{t}^{b}\right)^{\eta}\left(\frac{\left(a_{t+1}^{85}\right)^{1-\sigma}}{1-\sigma}\right)+\left(\frac{\left(c_{t}^{85}\right)^{1-\sigma}}{1-\sigma}\right)\right) .
\end{aligned}
$$

where $\beta \in(0,1)$ is the subjective discount factor. The problem facing the household, written in recursive form is

$$
V_{t}^{i}\left(a_{t}^{i}\right)=\max \left\{u_{t}^{i}\left(c_{t}^{c, i}, c_{t}^{i}\right)+V_{t+1}^{i+1}\left(a_{t+1}^{i+1}\right)\right\}
$$

subject to (1)-(2) and where $V_{t}^{86}\left(a_{t+1}^{86}\right)$ is $(4)$.

5

The age distribution affects household saving in two other key ways. First, relative cohort sizes affect intergenerational transfers. The saving rate increases when $n_{t}$ decreases because there will be fewer workers paying to support retirees in the future. Second, retirees leave bequests and the larger is the older generation, the more assets received by the current workers. Before examining the quantitative importance of demographic change for aggregate saving, we present details on the firm and the financial intermediary.

\subsection{Firm}

A representative firm with Cobb-Douglas technology in capital $K$ and labor $N_{t}^{w}$ produces output $Y$ according to

$$
Y_{t}=A_{t} K_{t}^{\alpha}\left(N_{t}^{w}\right)^{1-\alpha}
$$

Parameter $A$ measures total factor productivity (TFP), and $\alpha$ is the capital share. Labor is supplied inelastically by working age consumers so the aggregate labor input is $N_{t}^{w}=N_{t}^{p}$. Capital accumulates according to

$$
K_{t}=(1-\delta) K_{t-1}+I_{t}
$$

where $I$ is investment and capital depreciates at rate $\delta$. The firm seeks to maximize profits. As such, the wage it pays is the marginal product of labor

$$
w_{t}=(1-\alpha) \frac{Y_{t}}{N_{t}^{w}},
$$

\footnotetext{
${ }^{5}$ The value function of course also depends on which forms the exogenous portion of the state vector. We suppress the notational dependence on the exogenous portion of the state vector and implicitly recognize that dependence with the $t$ subscript on the functions.
} 
and pays a rental on capital that is the marginal product of capital less the depreciation rate

$$
r_{t}=\alpha A_{t} K_{t}^{\alpha-1}\left(N_{t}^{w}\right)^{1-\alpha}-\delta
$$

\subsection{Intermediation and Net Foreign Assets}

The capital stock is financed by an intermediary bank through foreign and domestic borrowing. Let $F_{t}$ be the number of internationally traded bonds held by the bank and $N_{t}^{i}$ be the number of people in cohort $i$ at date $t$. The net foreign asset position equals the difference between deposits (assets supplied by consumers) and loans (capital demanded by the firm)

$$
F_{t}=\underbrace{\sum_{i=18}^{85}\left(N_{t}^{i} a_{t}^{i}\right)}_{\text {deposits }}-\underbrace{K_{t}}_{\text {loans }} .
$$

\subsection{Equilibrium}

Equilibrium consists of the firm hiring labor and renting capital to maximize profits and each consumer selecting consumption and assets to maximize utility. Since labor supply is exogenously determined by the age distribution, the firm's labor demand pins down the wage $(w)$. We assume the interest rate equals the marginal product of capital net of the depreciation rate. The national demand and supply of assets need not be equal since the bank clears any excess on the international capital market.

\section{Parameterization}

The economy of China during the time-span of our data has been one in transition. Our parameterization of the model accounts for this transitional nature in the settings for labor's share $(1-\alpha)$ and in adult children's support $(\tau)$ for elderly parents. We begin with labor's share.

Two features of labor's share distinguishes China's economy from most developed economies: the share has declined over time and in recent years, has been comparatively low. Hu and Kahn's (1997) estimate of labor's share during the post-reform era is 0.4 which is quite a bit lower than the 0.66 share exhibited in the U.S. Hsieh and Klenow (2009) examine data from 1998 to 2005 and find that the median labor share across all state-owned firms and large non state-owned (revenues in excess of 5 million yuan) firms is 0.3 . Table 3 shows our own estimates using the Chinese national accounts data of labor's share for selected years. ${ }^{6}$ As a result of the declining labor share, wage growth has generally not kept pace with GDP growth in recent years.

\footnotetext{
${ }^{6}$ These estimates include nonwage compensation. Details of the methodology are given in the appendix.
} 
Table 3: Declining Labor Share

\begin{tabular}{llllll}
\hline \hline Year & 1960 & 1970 & 1980 & 1995 & 2007 \\
\hline Labor share & 0.64 & 0.57 & 0.59 & 0.53 & 0.48 \\
\hline
\end{tabular}

Taking into account our own calculations and by estimates in the literature, we allow for the declining labor share by setting $1-\alpha=0.6$ in the pre-reform years (1963-1978), then the share decreases by 0.02 per year between the years of 1979 and 1988 until it reaches 0.4 where it remains from 1989 onwards.

We now turn to the share of income $\tau$ transferred by workers to their elderly parents. A traditional characteristic of the Chinese family system has been that children, especially males, should care for their elderly parents. Presumably, the role of male children in this regard is a primary factor that underlies the preference for boys and the resulting sex imbalance exploited by Wei and Zhang (2009). Our parameterization of $\tau$ in the post-reform period is informed by the following. Xie and Zhu (2009) employ a survey conducted in 1998 to find that the (unconditional) fraction of income contributed by urban men to their parents is 0.03 . Surprisingly, they found little difference in the amounts given by urban women even though women earned substantially less than men. The (unconditional) fraction of women's income contributed was 0.06. Lee and Xiao (1998) employ a 1992 survey of children's support for elderly parents. Assuming a replacement rate of 0.66 , their results imply an unconditional transfer rate of 0.082 in the urban areas. If broken down by gender, the transfer rate is 0.037 for men and 0.16 for women. Information on the $\tau$ during the pre-reform period is scarce. As noted by Lee and Xiao, in those days, most people lived in the rural areas and belonged to collective production units with elderly persons receiving resources directly from the collectives. We view the payments from the collectives as the transfer share and set $\tau$ to be 0.12 in the pre-reform period. From 1979 to 1981, $\tau$ is reduced by 0.02 per year and remains at 0.05 from 1982 onwards. We set the post-reform $\tau$ on the low side of the estimates because a nontrivial proportion of adults in urban areas receive financial support from their elderly parents (Xie and Zhu (2009)).

We take the Barro-Becker children in utility parameters, $\mu=0.65$ and $\eta=0.76$, from Manuelli and Seshadri (2010). We set the time discount rate $(\beta)$ to 0.99 and the intertemporal elasticity of substitution $(1 / \sigma)$ to 0.53 . The capital deprecation rate $(\delta)$ is set to 0.10 . Table 4 summarizes the parameter values that we use. 
Table 4: Baseline parameterization

\begin{tabular}{|c|c|c|c|c|}
\hline Parameter & & Symbol & Value & Source \\
\hline weight on children & & $\mu$ & 0.65 & Manuelli and Seshadri (2009) \\
\hline concavity for children & & $\eta$ & 0.76 & Manuelli and Seshadri(2009) \\
\hline \multirow[t]{4}{*}{ labor's share of output } & \multirow[t]{2}{*}{ pre-reforms } & \multirow[t]{2}{*}{$(1-\alpha)$} & \multirow[t]{2}{*}{0.6} & Author's calculations \\
\hline & & & & Hu and Khan (1997) \\
\hline & \multirow[t]{2}{*}{ post-reforms } & & \multirow[t]{2}{*}{0.4} & Hsieh and Klenow (2009) \\
\hline & & & & Author's calculations \\
\hline \multirow[t]{3}{*}{ transfer share } & pre-reforms & $\tau$ & 0.12 & \\
\hline & \multirow{2}{*}{ post-reforms } & & \multirow{2}{*}{0.05} & Lee and Xiao (1998) \\
\hline & & & & Xie and Zhu (2009) \\
\hline discount rate & & $\beta$ & 0.99 & standard \\
\hline coef. of relative risk aversion & & $\sigma$ & 1.9 & standard \\
\hline depreciation rate & & $\delta$ & 0.10 & standard \\
\hline
\end{tabular}

\section{$5 \quad$ Results}

Initial assets are set near zero. When we get to the end of the sample, the 18 year old agent needs to look forward an additional 68 years to solve his/her problem in 2008. The future demographic data come from the United Nations projections. Future wage and interest rate observations are generated by assuming a gradual transition of the growth rate to a steady state rate of 2.0 percent with a half-life of adjustment of 12 years. $^{7}$ The 1950s in China were a time of massive policy initiatives, reversals and disasters (e.g., the Great Leap Forward, the Great Famine). Due to the volatility in the data at that time, we begin our simulation results after the Great Famine in 1963.

Our baseline simulation results using the parameterization from Table 4 is shown in Figure 5. As in the data, the model exhibits relatively low saving rates before the mid 1970s and a sharply rising saving rate around the time of the economic reforms. By 2008, the model generates a saving rate that of 0.25 which is only slightly less than the 0.27 rate in the data. e. There is a good deal in the model saving rates in the 1960s which is driven in part by high labor income volatility at that time The model generates the saving boomlet and decline in the 1980s but does not exactly match up in terms of timing. From 1990 to 1995 the implied saving rate rises and matches the increase in the data. The saving rate in the data continues to increase through 1999 and is then flat until 2005. The model also generates a flat saving rate during those years, although at a lower level. The implied saving rate resumes its upward trend from 2005 onward. In short, the model is able, with varying degrees of success, to account for (i) the generally high rate of post-reform household saving, (ii) the trend break in the saving rate, and (iii) cyclical fluctuations in the saving rate.

Figure 6 shows 2009 saving rates by cohorts implied by the model. It displays the standard hump shape with the saving rate reaching its maximum with the cohort in the last year of em-

\footnotetext{
${ }^{7}$ Similarity to Chen et al.
} 
ployment. Cohorts aged 80 and older dissave.

There are several facets of the model that and sources of data variation that are key to generating these saving dynamics. We now investigate the contributions of these factors by shutting off various features of the model.

Experiment 1 (Varying family size). See Figure 6. The line with ' $\mathrm{x}$ ' markers is generated by setting the parameter $\mu$ to zero, which kills off explicit valuation of dependent children's consumption in household utility. Chen et al and Ferrero ignored dependent children's consumption so this gets closer to models considered by them. Ignoring dependent children causes the saving rate implied by the model to be too high and for most of the sample it overstates the saving rate. The 'no children' saving rate is starts increasing much too soon by beginning in 1970. It reaches a peak of 0.28 in 1979 then trends downwards from that point. It is clear that not only is the 'no children' saving rate generally too high but it also misses the timing of the trend breaks.

The series marked by inverted triangles is generated assuming a constant family size of $n=2$ children per (single head of) household. The economy with big families usually generates an aggregate household saving rate that lies below our baseline rate. From 1964 to 1972, only a trivial saving rate emerges. The implied timing of the trend reversals in the 'big family' economy matches that of the baseline model. The conclusion from this experiment is that fewer (more) children in the family causes households to behave as if they are more (less) patient.

To see why this occurs, let us return to the preferences of parents with dependent children, eq. (3). Here, $\left(c_{t}^{c}\right)^{1-\sigma} /(1-\sigma)$ the per child utility which is scaled up by a function that is increasing in the number of children in the household. Since household utility is increasing in both the number of children and consumption per child, there are two factors to incentive larger families to expend resources on additional consumption instead of saving. The idea that increasing the number of dependent children makes the household behave as if it is less patient is formalized in

Proposition 1: (Effective Discount Rate) The first term of the utility function (3) can be written as

$$
U_{t}=\sum_{j=0}^{30} \widehat{\beta}_{j} \frac{c_{t+j}^{j+18}}{1-\sigma}
$$

where $\widehat{\beta}_{j}$ is the effective discount rate, such that

$$
\widehat{\beta}_{j}=\beta^{j}\left(1+\left[\mu n_{t+j}^{-\left(\sigma^{2}-2 \sigma+1-\eta\right)}\right]^{1 / \sigma}\right)
$$

is decreasing in $n_{t+j}$ if $\sigma<1-\sqrt{\eta}$ or if $\sigma>1+\sqrt{\eta} .{ }^{8}$

The effective discount factor under our parameterization of preferences is decreasing in $n$, since $\sigma=1.9>1+\sqrt{\eta}=1.87$.

\footnotetext{
${ }^{8}$ We thank Joe Kaboski for suggesting Proposition 1. We note that Choi and Mark (2009) show that variation in the time discount rate $(\beta)$ across countries can explain the trending current accounts in Japan and the US. Our model is consistent with the Choi and Mark hypothesis, in that different age structures generate different time discount factors, as demonstrated by Proposition 1 .
} 
Experiment 2 (No bequest motive). Figure 8 shows the results from turning off the bequest motive. Cohorts in the last period of life consume the entire value of their accumulated assets and income support obtained from their adult children. As can be seen, our baseline results are robust to whether a bequest motive is in effect or not.

Experiment 3. (Smoothed wages, reduced wage growth). See Figure 9. We first smooth out wage fluctuations by passing the marginal product of labor through the Hodrick-Prescott filter. The implied saving rate obtained when workers receive the HP trend of wages is shown with ' $\mathrm{x}$ ' markers. Eliminating the cyclical fluctuations in the wage does not impact the model in a substantive way. The implied saving rate and implied trend breaks are very similar to those in the baseline model. The series with triangle markers is generated by assuming that real wage growth is reduced by 80 percent. As expected, low wage growth induces high saving rates.

Experiment 4 (Static expectations). In solving the model, we have assumed that households have perfect foresight with respect to the evolution of the interest rate, wage, and demographics. Outside of economics, this may strike one as a heroic assumption. Even within economics, perfect foresight can seem a bit strong. A strongly contrasting assumption that we investigate is that households form static expectations. In this experiment we assume at each date, the household assumes that all future values of the exogenous variables are fixed at currently observed values. The results, displayed in Figure 10, show that assuming static expectations would be a poor modeling choice. The implied saving rate is much too high and trends in the wrong direction after the reforms. We conclude that while perfect foresight may be unrealistic, we draw on Friedman's (1966) recommendation to view agents as behaving as if they have perfect foresight but not that they necessarily possess this attribute.

\section{Conclusion}

We have shown that standard life-cycle considerations can explain the evolution of household saving in China from 1963 to 2008. Two features are central to our analysis: First, young dependent children should enter explicitly into household utility and second, the changing age distribution of the entire economy should be represented. The rapid rate of labor income growth in recent years works to depress household savings. It thus follows from our analysis that the presently high saving rate is driven primarily by the reduction in family size resulting from population control policies and the relatively large size of the today's working population.

As the Chinese population ages, and it is aging quite rapidly, the rising household saving rate should be arrested. Presently observed Chinese external surpluses, to the extent that they are driven by household saving, should also be a temporary phenomenon. 


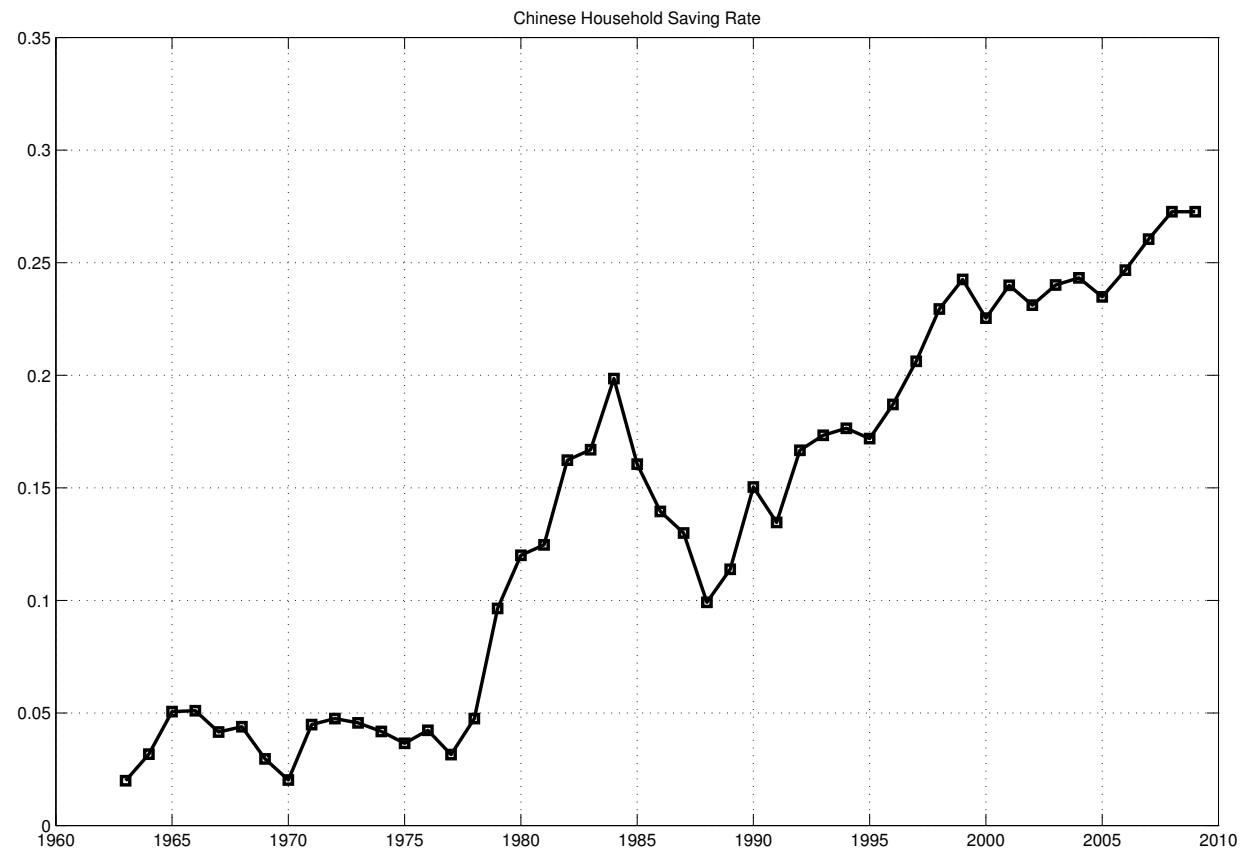

Figure 1: Household saving rate in China

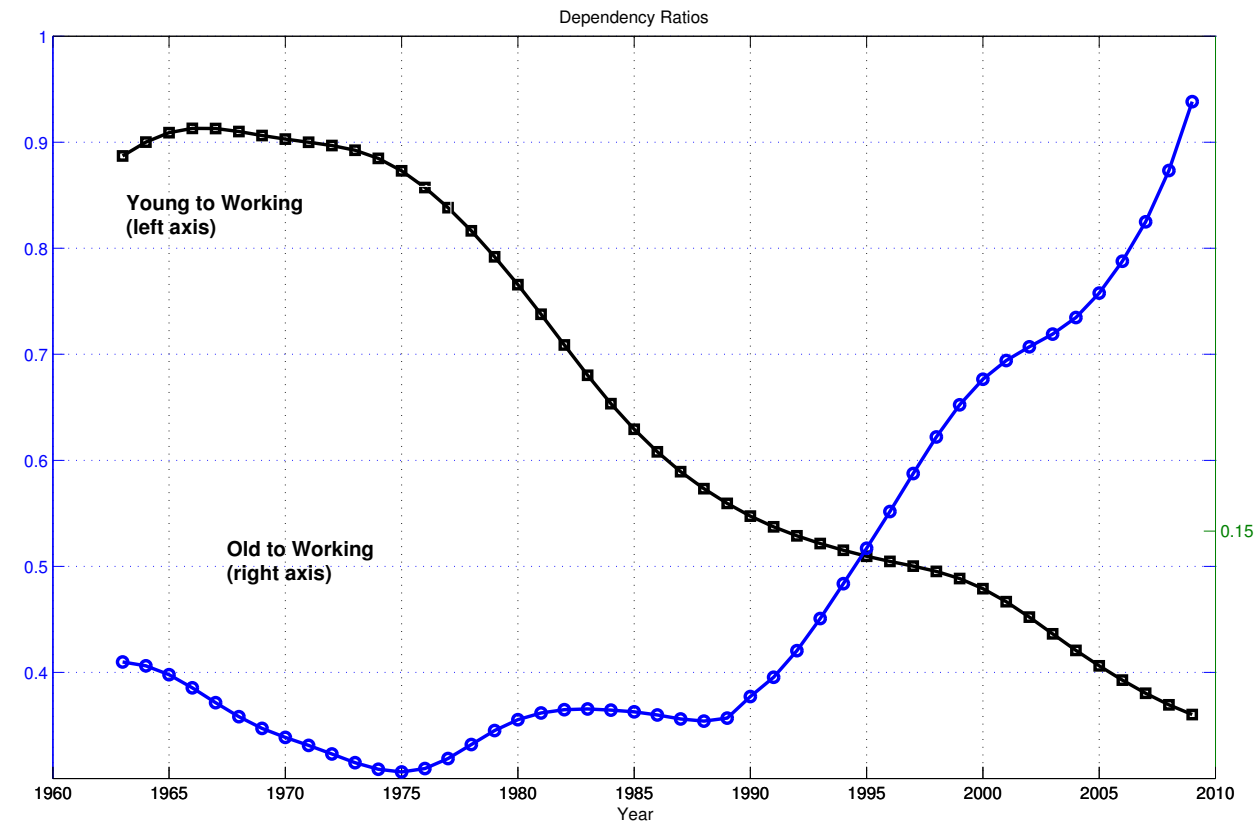

Figure 2: Demographic variation 


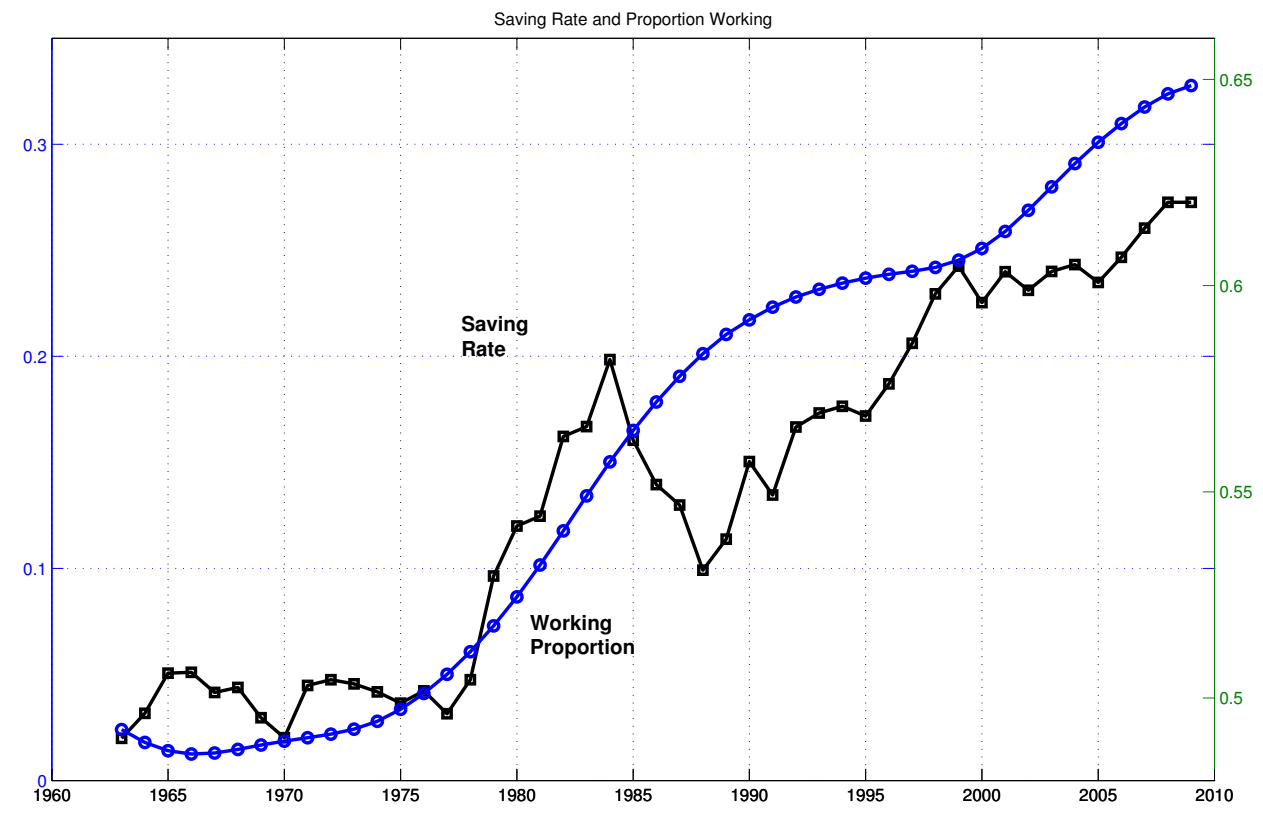

Figure 3: Saving rate and proportion of working population

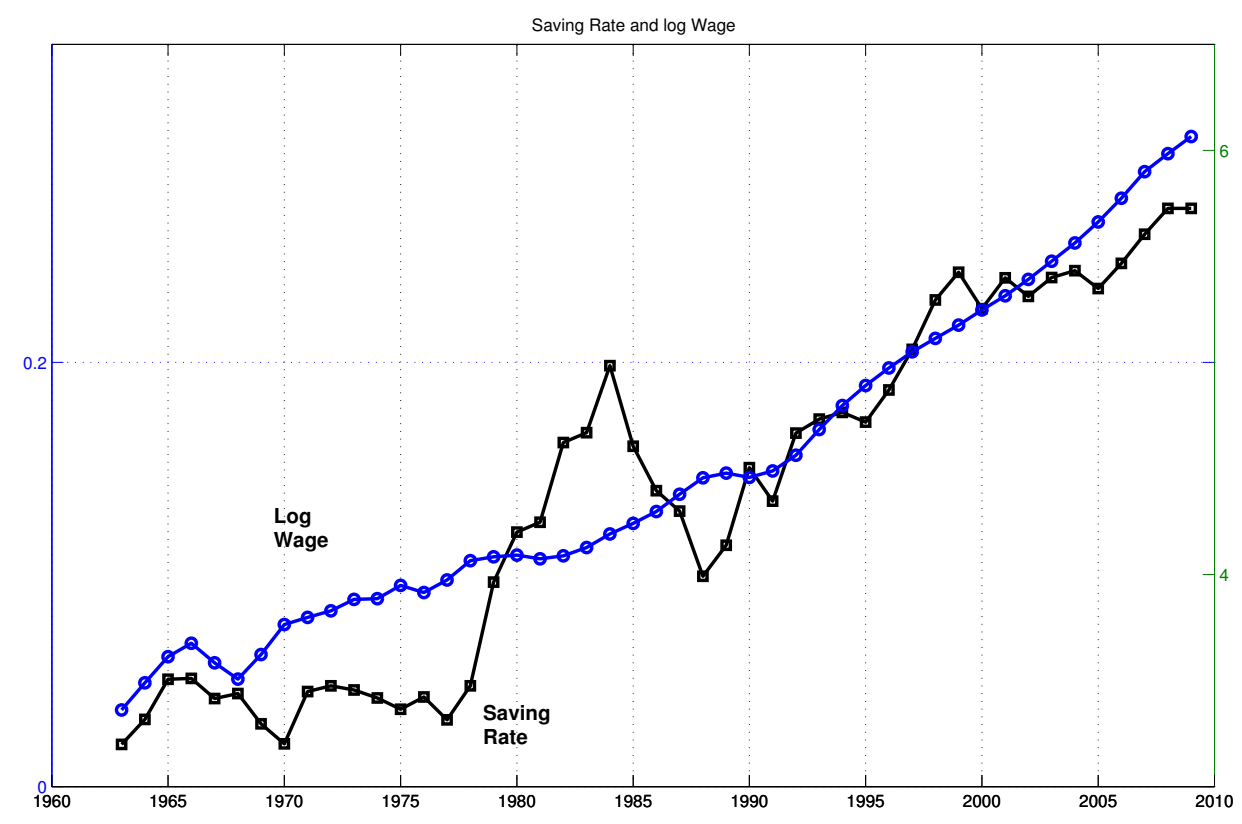

Figure 4: Saving rate and log real wage 


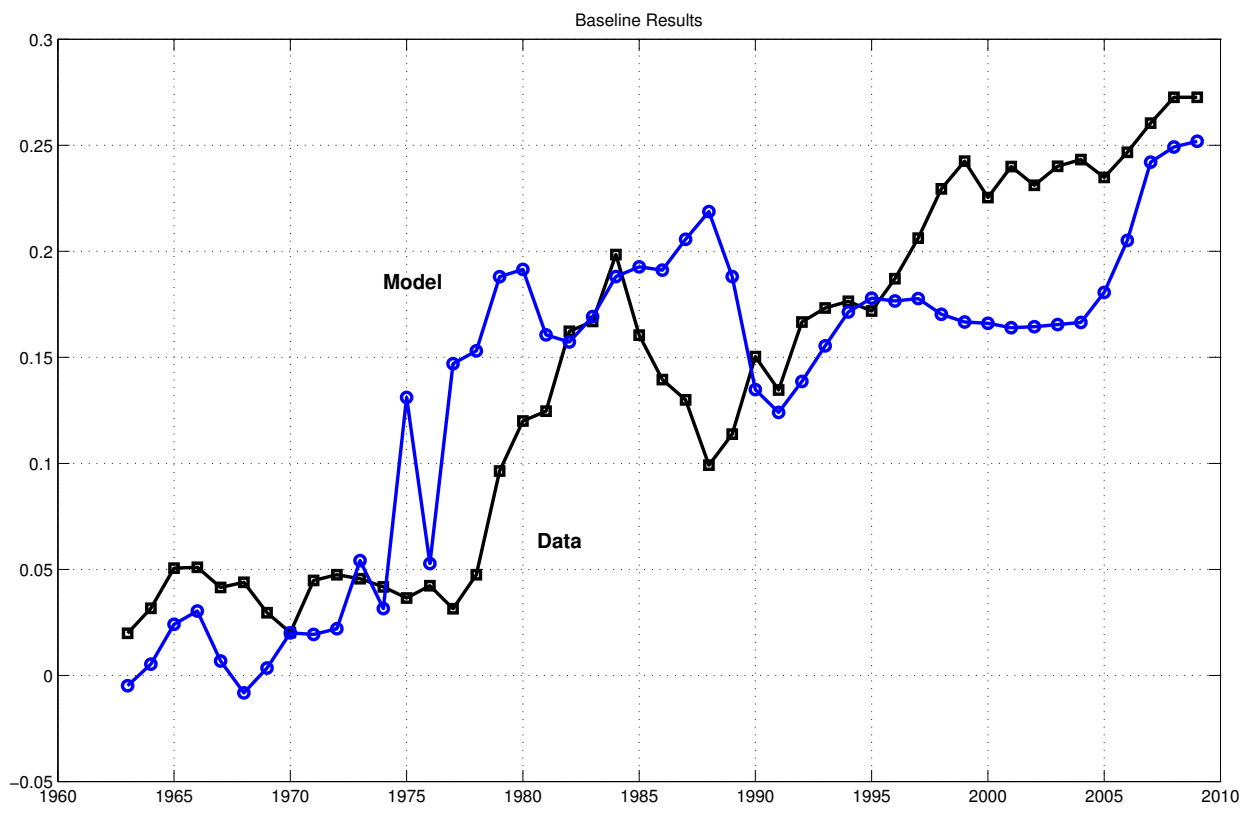

Figure 5: Baseline results

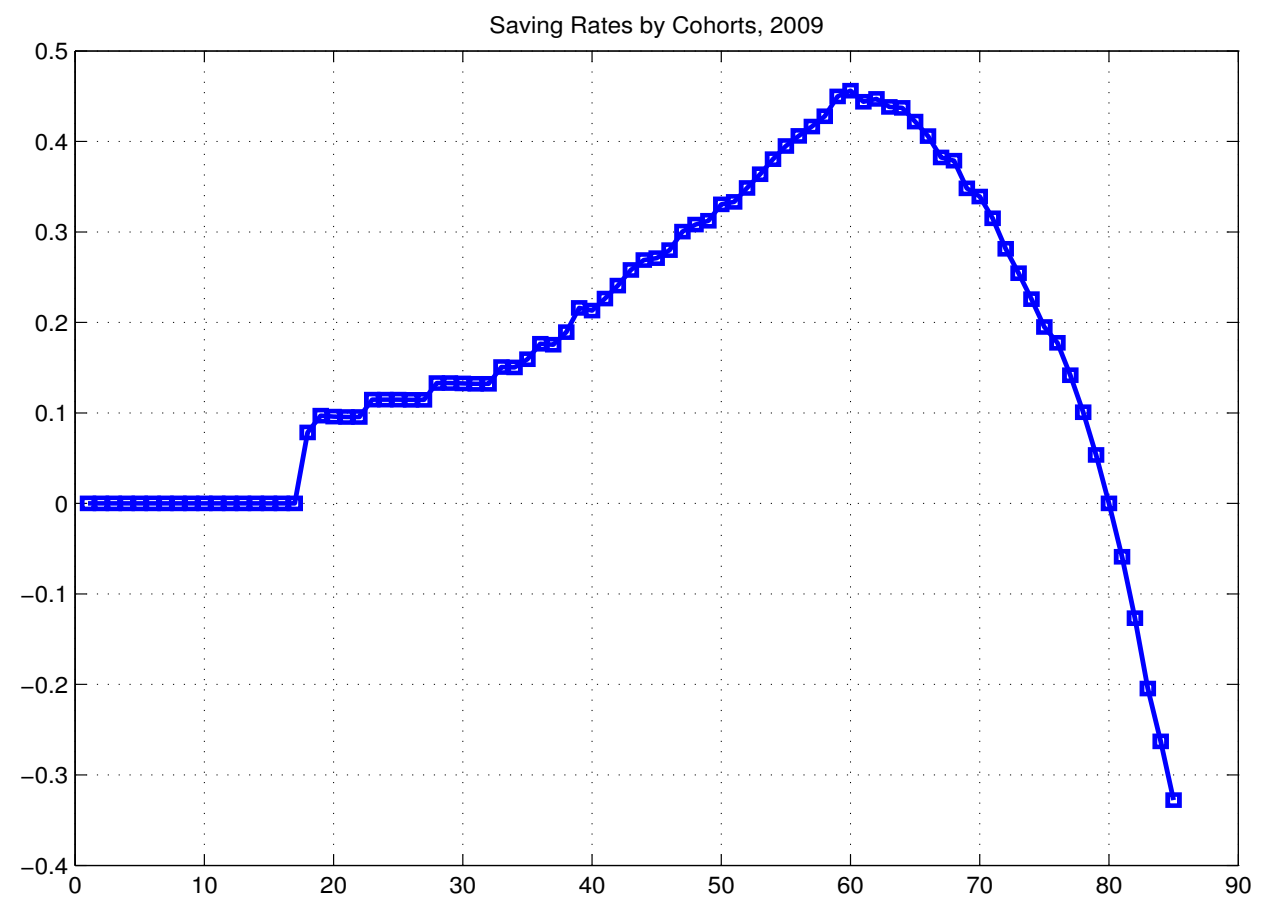

Figure 6: Implied saving rates by cohort in 2009. 


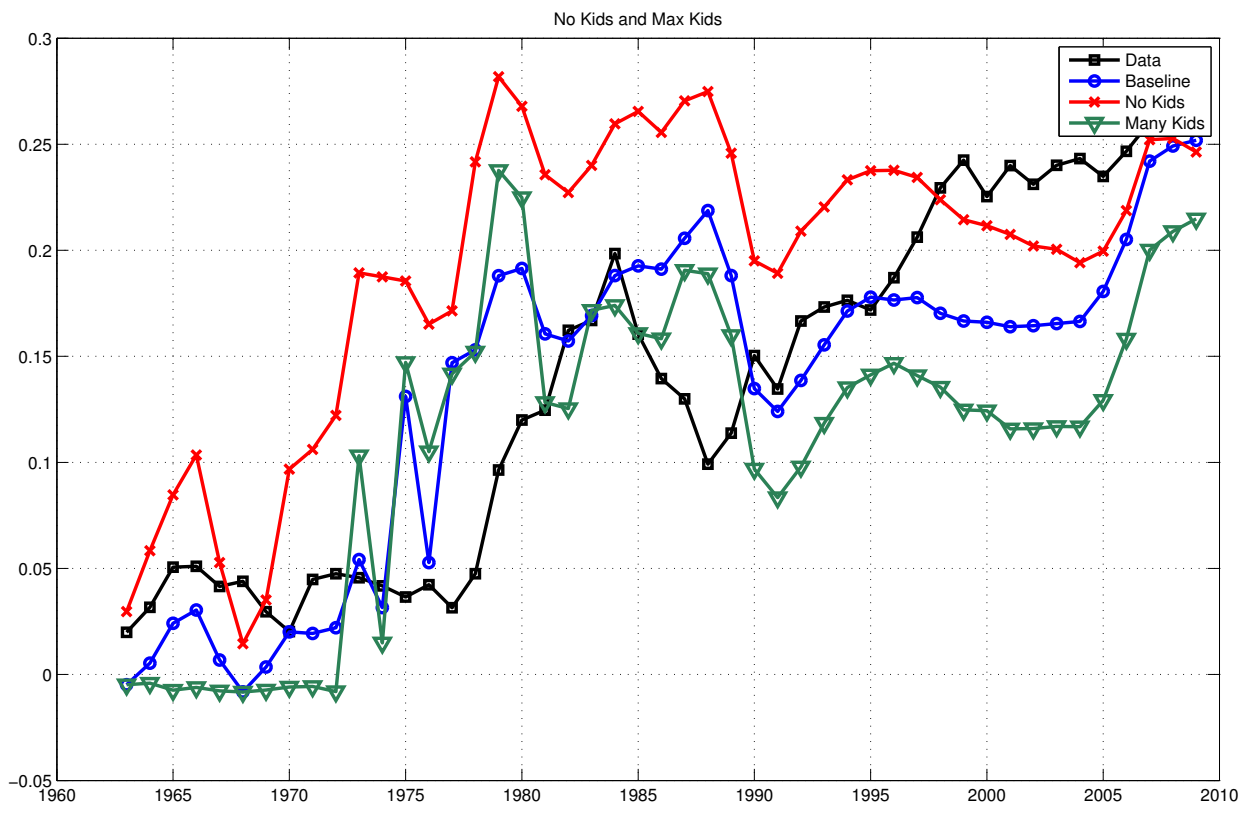

Figure 7: Family size variation (experiment 1)

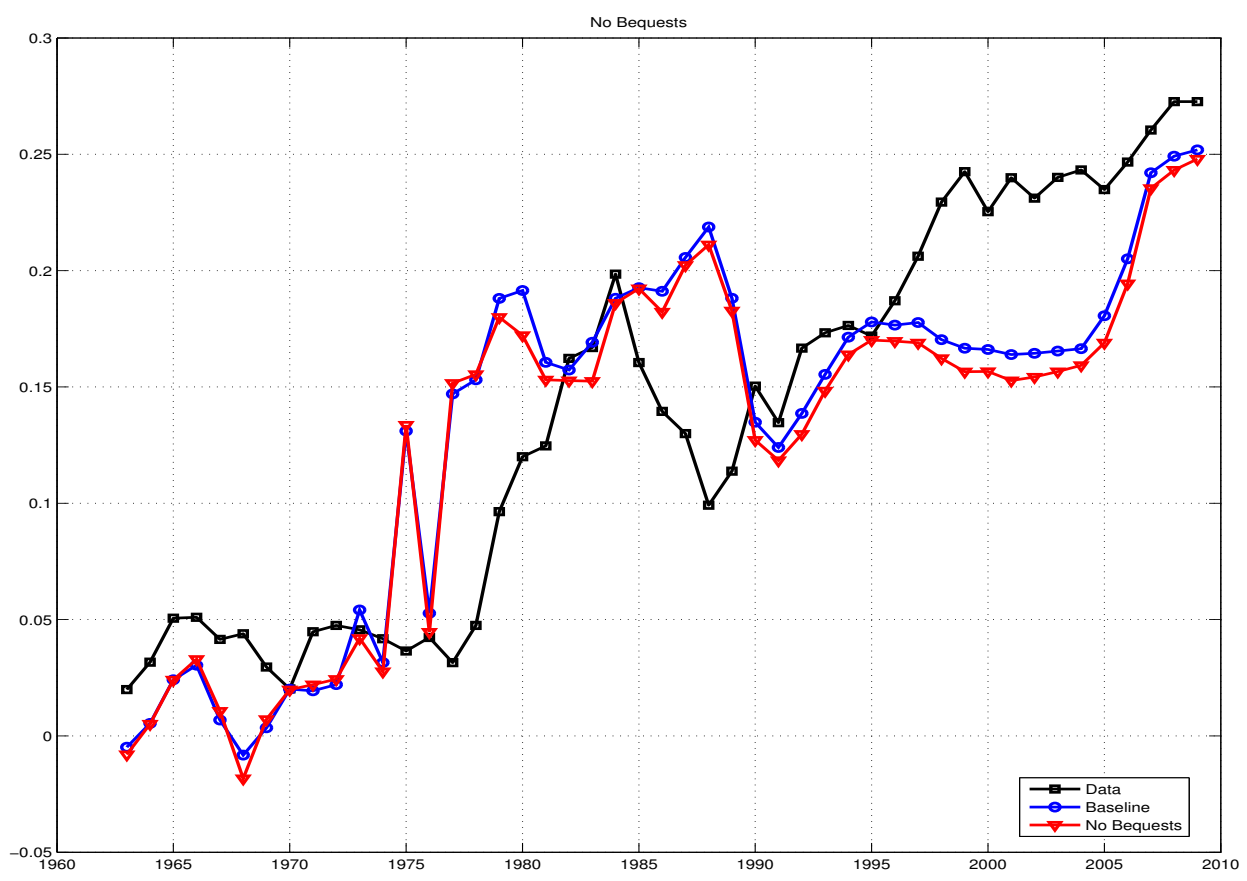

Figure 8: No Bequests (experiment 2) 


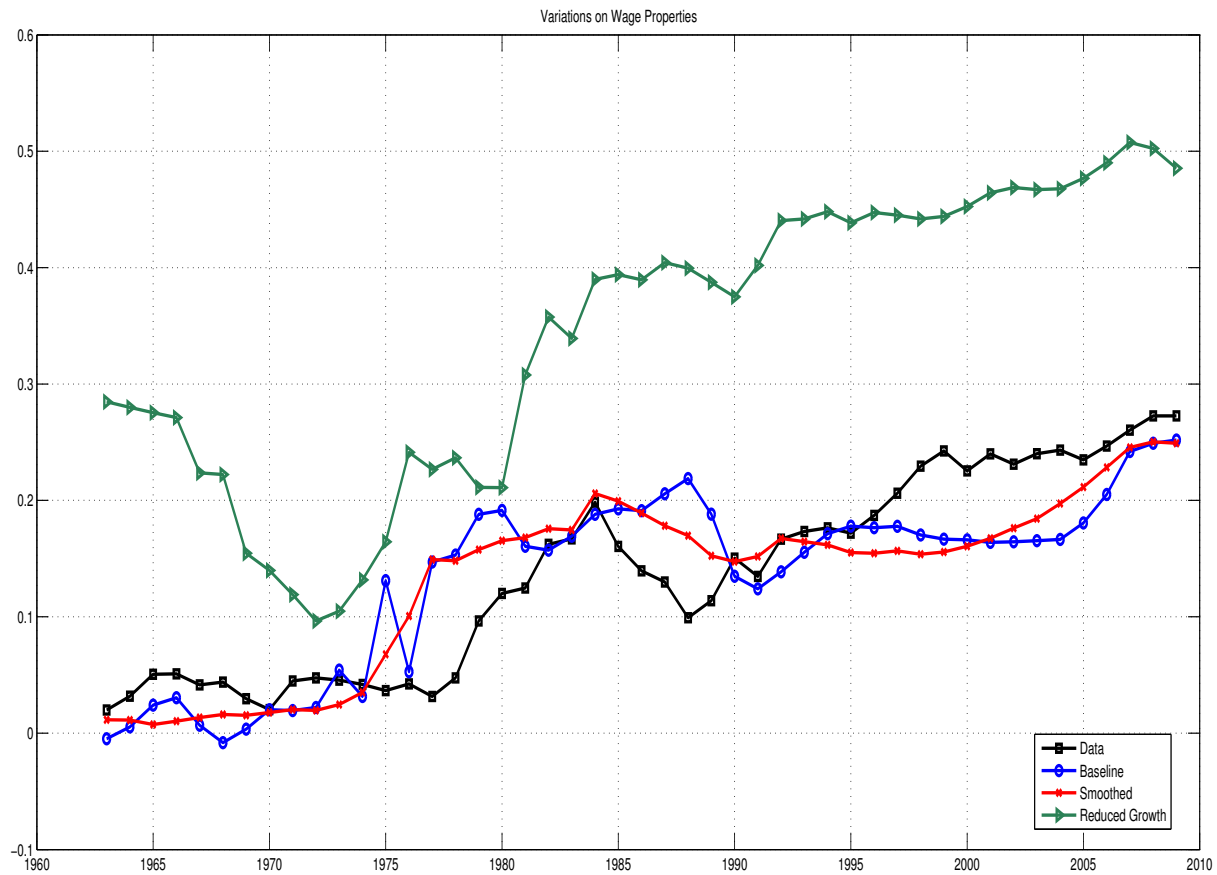

Figure 9: Variations on the real wage (experiment 3)

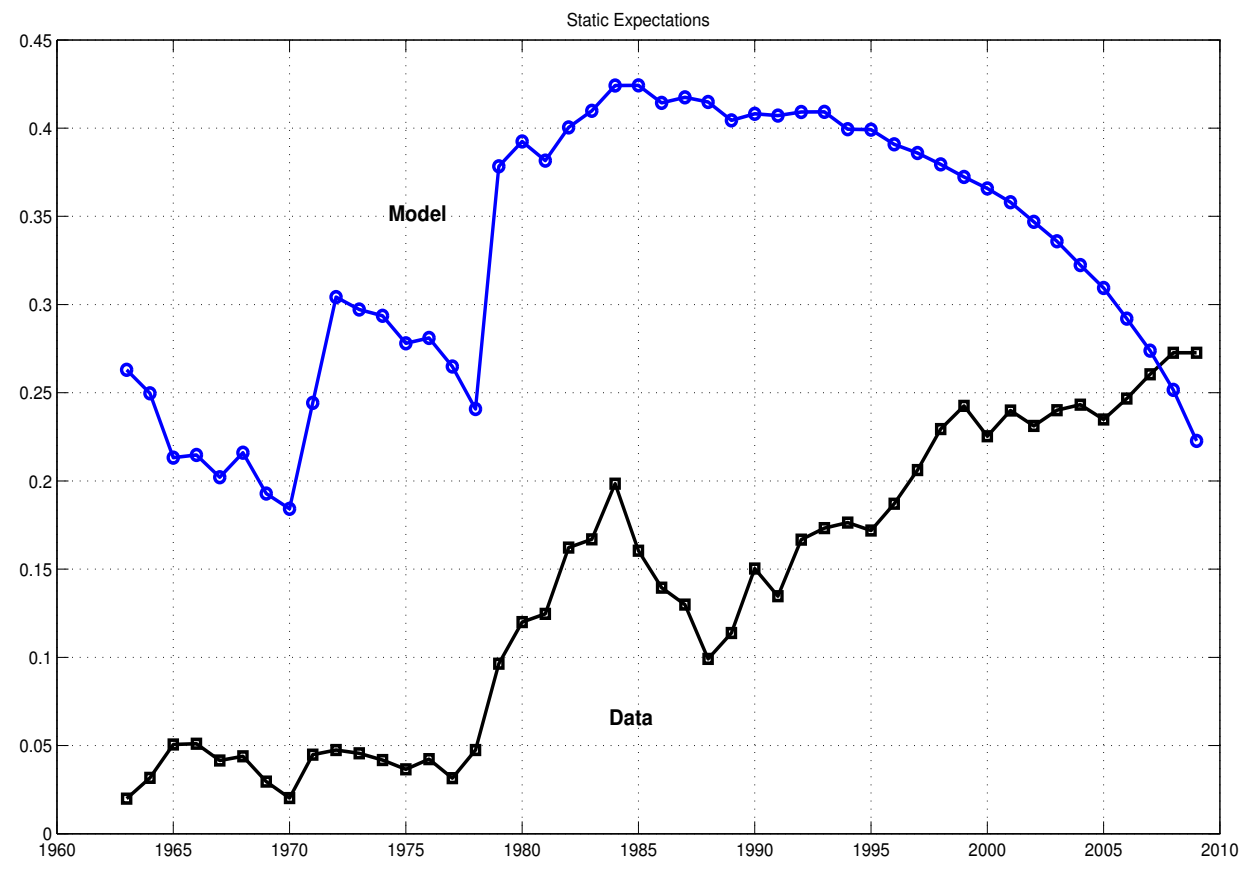

Figure 10: Static expectations (experiment 4) 


\section{References}

[1] Banerjee, Abhijit, Xin Meng, and Nancy Qian, (2010). "The Life Cycle Model and Household Savings: Micro Evidence from Urban China," mimeo, Yale University.

[2] Barro, Robert J. and Gary S. Becker, (1989). "Fertility Choice in a Model of Economic Growth," Econometrica, Vol. 57, No. 2 pp. 481-501

[3] Chamon, Marcos and Eswar Prasad, (2010). "Why Are Saving Rates of Urban Households in China Rising?" American Economic Journal: Macroeconomics 2010, 2:1, 93-130.

[4] Chen, Kaiji, Ayşe İmrohoroğlu, and Selahattin İmrohoroğlu, (2007). "The Japanese Saving Rate Between 1960 and 2000: Productivity, Policy Changes, and Demographics," Economic Theory, 32, pp. 87-104.

[5] Curtis, Chadwick R. and Nelson C. Mark, (2010). "Business Cycles, Consumption and RiskSharing: How Different Is China?" forthcoming inYin-WongCheung,Vikas Kakkar and Guonan Ma, eds., The Evolving Role of Asia in Global Finance.

[6] Ferrero, Andrea, (2010). "A Structural Decomposition of the U.S. Trade Balance: Productivity, Demographics, and Fiscal Policy," Journal of Monetary Economics, 57(4), pp. 478-490.

[7] Feyrer, James, (2007). "Demographics and Productivity," Review of Economics and Statistics, 89(1), pp. 100-109.

[8] Friedman, Milton, (1966). "The Methodology of Positive Economics" In Essays In Positive Economics (Chicago: Univ. of Chicago Press), pp. 3-16, 30-43.

[9] Hoiroka, Charles Yuji and Junmin Wan, (2006). "The Determinants of Household Saving in China: A Dynamic Panel Analysis of Provincial Data," Journal of Money, Credit, and Banking, 39(8), pp. 2077-96.

[10] Hu, Zuliu F. and Mohsin S. Khan, (1997). "Why is China Growing So Fast?" Staff PapersInternational Monetary Fund, 44(1), pp. 103-131.

[11] Jaimovich, Nir and Henry E. Siu, (1997). "The Young, the Old, and the Restless: Demographics and Business Cycle Volatility" American Economic Review, 99(3), pp. 804-826.

[12] Kaufman, Joan, Zhang Zhirong, Qian Zinjian and Zhang Yang, (1989). "Family Planning Policy and Practice in China: A study of Four Rural Counties," Population and Development Review, 15,(4), pp. 707-29.

[13] Krueger, Dirk and Alexander Ludwig, (2007). "On the Consequence of Demographic Change for Rates of Returns to Capital, and the Distribution of Wealth and Welfare," Journal of Monetary Economics, 54(1), pp. 49-87. 
[14] Lee, Jean-Yu and Zhenyu Xiao, (1998). "Children's support for elderly parents in urban and rural China: Results from a national survey," Journal of Cross-Cultural Gerontology 13: 3962.

[15] Lugauer, Steven, (2010). "Estimating the Effect of the Age Distribution on Cyclical Output Volatility Across the United States," mimeo, University of Notre Dame.

[16] Manuelli, Rodolfo and Ananth Seshadri, (2010). "Explaining International Fertility Differences," Quarterly Journal of Economics, Forthcoming.

[17] Modigliani, Franco and Shi Larry Cao, (2004). "The Chinese Saving Puzzle and the Life-Cycle Hypothesis," Journal of Economic Literature, 42, pp. 145-170.

[18] Shimer, Robert, (2001). "The Impact of Young Workers on the Aggregate Labor Market," Quarterly Journal of Economics, 116(3), pp. 969-1007.

[19] Song, Zheng Michael and Dennis Tao Yang, (2010). "Life Cycle Earnings and Saving in a Fast-Growing Economy," mimeo, Chinese University of Hong Kong.

[20] Wei, Shang-Jin and Xiaobo Zhang, (2009). "Sex Ratios and Savings Rates: Evidence from "Excess Men" in China," mimeo, Columbia Business School

[21] Wu, Zuliu and Mohsin Khan, (1997). "Why is China Growing so Fast?," Staff Papers - International Monetary Fund, 44(1), pp. 103-131. 